\title{
O referendo como forma de consolidação da democracia: o exemplo da descriminalização do aborto
}

\section{The referendum as a way of democracy consolidation: the example of abort decriminalization}

\author{
Roberto Lauro Lana \\ Faculdade de Medicina de Teresópolis (FESO), Teresópolis, Rio de Janeiro, \\ Brasil. \\ robertolana@uol.com.br
}

\begin{abstract}
Resumo: Trata o presente artigo de considerações a respeito do recente referendo popular realizado em Portugal, com relação à descriminalização materna do aborto nas gestações com duração inferior a dez semanas. Previamente, divulgou-se por todos os meios de comunicação em áudio, audiovisual e escritos, um amplo debate relacionado ao tema sob votação, refletindo as diversas opiniões dos atores sociais nela envolvidos, políticos, médicos, clero, intelectuais, associações pró e contra o aborto, e o público em geral. As conclusões são expostas e discutidas, principalmente em relação à realidade e às práticas brasileiras.
\end{abstract}

Palavras-chave: Referendo português. Legislação. Aborto. Descriminalização.

\begin{abstract}
The article deals with considerations about a recent poll survey held in Portugal concerning maternal decriminalization of abortion before 10th. weeks of pregnancy. It was preceded by wide debate in the mass media involving different opinions such as those from politicians, doctors, clergymen, intellectuals, associations pro-choice and pro-life, and general public. Those conclusions are exposed and discussed mainly in their relation to Brazilian reality and practices.
\end{abstract}

Key words: Portuguese Referendum. Legislation. Abortion. Decriminalization.

\footnotetext{
A principal característica das sociedades democráticas é a garantia da participação popular nas decisões sobre as questões morais e legais que afetam o cotidiano dos cidadãos. Esta participação garante que a vontade da maioria dos cidadãos se reflita em políticas de Estado.
} 


\section{Revista Brasileira de Bioética}

O voto é a forma escolhida para levantar qual seria a vontade dos cidadãos nas democracias ocidentais que, comumente, adotam a democracia de forma representativa. Este sistema de governo pressupõe que os representantes escolhidos pelo povo sejam capazes de responder a suas necessidades por meio de legislações que exprimam a moralidade do conjunto da sociedade. Porém, ainda que o sistema representativo seja, inequivocamente, um avanço em relação aos regimes totalitários, cabe a dúvida se esses representantes, mesmo eleitos pelo voto direto, defendem posições que representem a vontade da maioria. Pode-se inferir tal questionamento na freqüência com que alguns assuntos de cunho moral e legal têm vindo à baila nas diferentes sociedades.

Tal é o caso da descriminalização do aborto, tema recorrente e apaixonante, que sempre que é trazido ao debate público provoca as mais diversas tendências e opiniões (1). Da mesma maneira, a descriminalização do uso de drogas constitui foco de polêmica, fundado em argumentos de várias naturezas. Há, evidentemente, a perspectiva dos sociólogos e educadores, dos médicos e outros representantes da ciência oficial, dos filósofos e teólogos, dos juristas e criminalistas, dos eclesiásticos e das numerosas correntes de pensamento religioso, do público laico, enfim, de toda a sociedade civil (organizada ou não), sejam eles homens ou mulheres, estas em idade reprodutiva, ou não. Estas distintas perspectivas mostram que tais questões são polêmicas e que, talvez, o sistema representativo de participação popular não seja capaz de refletir a moralidade social.

Para discutir esse ponto de vista, nada melhor que tomar como exemplo o aborto, questão impactante que é constantemente trazida ao debate público em diversas sociedades, como está acontecendo no Brasil no ano 2007. Que o aborto é considerado crime pela sua tipificação nos artigos 124 a 126 do Código Penal Brasileiro de 1940, não se discute (2). O Código abre apenas duas exceções previstas no Artigo 128: a do aborto por gravidez decorrente de estupro; ou para salvar a vida da mãe, chamado aborto necessário. As demais causas que ensejam o processo de abortamento conduzido pela mãe ou por terceiros, são severamente punidas pela legislação em vigor (2). Não se exclui nem mesmo a má-formação fetal, as chamadas anomalias fetais, muitas das quais são incompatíveis com a vida extra-uterina, 
causa justificativa de aborto já bem estabelecida, desde há muitas décadas, em diversos países.

Em decorrência dessa legislação, mulheres com gravidez indesejada são induzidas a recorrer aos serviços criminosos de aborteiros ou "curiosos" de plantão, sempre caros e até inacessíveis para a maioria, expondo-se a riscos de morte e infecção com seqüelas indesejáveis pelo resto de suas vidas. Não há a menor possibilidade de serem atendidas pelos hospitais e maternidades públicas, algumas vezes nem mesmo nas situações em que a lei autoriza, como no caso de estupro.

Tal circunstância, que implica no adoecimento e na morte de milhares de mulheres anualmente, pode estar relacionada aos fenômenos sociais das crianças abandonadas e do aumento da ocorrência de gravidez em adolescentes, sendo possível que esteja associada também, indiretamente, à crescente pauperização da população, aos casos das famílias inteiras sem teto e dormindo nas ruas, bem como dos menores delinqüentes. Frente a tal quadro é impossível simplesmente fechar os olhos para essa questão, que atinge tão particularmente as mulheres e que repercute em toda sociedade. Talvez por isso o Ministro da Saúde, José Gomes Temporão, tenha se pronunciado sobre o assunto, apresentando-o à sociedade como questão de saúde pública.

Apresentada dessa forma, a questão do aborto ilustra a necessidade de deflagrar processos democráticos que possam promover transformações sociais e superar os preconceitos. Isso se torna mais importante quando se considera a crescente pressão exercida sobre a sociedade pelas mazelas decorrentes da contradição do Brasil ser um país em crescimento num contexto globalizado, o que concorre para que a população torne-se cada vez mais empobrecida e desassistida. Tal processo, que acentua a desigualdade, ocorre sob o olhar indiferente daqueles que deveriam se preocupar com esse quadro alarmante que decorre da desigualdade social. Isso evidencia que, para consolidar o regime democrático de direito em uma sociedade laica, este tema (assim como outros que afetam profundamente a moralidade social) deve ser debatido e decidido pela sociedade civil. Somente a ela cabe se manifestar em que sentido deseja que a legislação seja orientada, a exemplo do que ocorre em diversos países e, recentemente, em Portugal. 


\section{Revista Brasileira de Bioética}

Porém, para que tal debate leve à superação do impasse moral que envolve esse tema, há necessidade de uma ampla discussão pública. Tais discussões cumprem o propósito de informar a sociedade sobre o assunto, permitindo que a tomada de posição sobre o mesmo possa ser feita, de fato, a partir da reflexão. Desse modo, acredita-se, poderiam ser revistos e analisados alguns conceitos morais atualmente vigentes que fundamentam as posições pró e contra o aborto no país, algumas delas francamente preconceituosas, segundo seja pela ótica médica, jurídica, religiosa ou ética.

\section{Discussão em Portugal}

Um grande debate público sobre o aborto ocorreu recentemente, durante o mês de fevereiro de 2007, em Portugal. A importância disso decorre daquele país ser a matriz colonizadora do Brasil, além da forte tradição religiosa católica com relação à descriminalização do aborto. A descriminalização do aborto foi proposta à sociedade e avaliada em referendo popular pelo voto não-obrigatório. Após intensa campanha, com debates nos meios de comunicação, principalmente na televisão, mas também por meio de outdoors, cartazes, palestras e artigos nos jornais, toda a sociedade se engajou na luta pró ou contra o aborto, comparecendo às urnas e manifestando-se conscientemente. É importante destacar que o Referendo português de 2007 contou com significativa maioria popular, ao contrário do outro semelhante, realizado em 1998, que foi por este motivo anulado.

Um aspecto importante dos argumentos que poderiam (e deveriam) ser utilizados pró ou contra o aborto, mas que não foram destacados nas discussões, é o de ordem demográfica. Portugal, país com cerca de 10 milhões de habitantes, cuja população vem se reduzindo proporcionalmente ao longo das últimas décadas, congrega expressiva população de imigrantes, oriunda principalmente de ex-colônias africanas, que somam aproximadamente um milhão de habitantes. Certamente, são esses migrantes que mais se beneficiariam da nova legislação a ser posta em prática e, conseqüentemente, haveria uma estabilização natural da relação cidadão nativo/imigrante nos patamares atuais, embora tal análise desconsidere novos fluxos migracionais que deverão ocorrer no futuro. 
Outro fator adicional é que dos 25 países membros da Comunidade Européia da qual Portugal faz parte apenas três, Portugal, Malta e Irlanda, ainda opunham restrições ao aborto em suas respectivas legislações. Os demais países, mesmo os de forte tradição religiosa, como Espanha, Itália e França, já alteraram suas leis há alguns anos, adotando posições liberalizantes com relação ao aborto. O anacronismo da lei portuguesa em relação aos países vizinhos deixava como única opção legal às mulheres portuguesas que considerassem necessário interromper a gravidez, atravessar a fronteira com a Espanha e realizar o aborto num serviço público local daquele país, fato amplamente divulgado na campanha pró-aborto.

É importante ressaltar, também, a experiência da Romênia, que recentemente passou a integrar a Comunidade Européia. Em 1988, o Congresso Romeno revogou a legislação que, desde 1966, permitia a prática do aborto. No entanto, já no ano seguinte, viu-se obrigado a cancelar a nova legislação devido à elevação da mortalidade materna em conseqüência de abortos clandestinos. Naquele período, a taxa subiu acentuadamente, de 80 para 180 mortes em cada 100 mil partos, retrocedendo, em seguida, após a alteração da legislação, aos níveis de 40 por 100 mil. Vale lembrar que, no Brasil, segundo estatísticas oficiais do Ministério da Saúde (MS), morrem cerca de 70 mil mulheres entre 10 a 49 anos por ano devido às complicações causadas por abortos clandestinos.

A campanha portuguesa pela manutenção da legislação em vigor embasou-se, principalmente, no princípio da sacralidade da vida humana e na tutela dos direitos do nascituro. Abordando de maneira enfática a discussão, manteve os argumentos tradicionais à legalização do aborto. Evidentemente, tais condições impeditivas (e radicalmente contrárias) à interrupção da gravidez são, desde há séculos, impostas pela Igreja Católica Apostólica Romana, com inegável predomínio entre a população de Portugal.

A descriminalização do aborto foi posição tomada pela sociedade portuguesa, vitoriosa nas urnas na proporção de 51\% a 38\%. Imediatamente após esta constatação, em prazo bastante curto, foi elaborada pelo Congresso português uma nova legislação, submetida à sanção presidencial e logo assinada, oficializando, dessa maneira, o aborto por opção materna até a $10^{\mathrm{a}}$ semana de gravidez, inclusive nas ma- 


\section{Revista Brasileira de Bioética}

ternidades públicas. O exemplo português reforça a tese, já comprovada em outros países europeus, como a Itália, que demonstra que, quando esclarecida, a população é capaz de alterar os aspectos de sua moralidade que implicam em dano físico e moral para o conjunto da sociedade.

\section{Referendo como meio de consulta popular}

O referendo, como meio de consulta popular, já demonstrou - sobejamente - ser uma prática altamente democrática, inserida na maior parte das constituições dos países cujo regime de governo pretende estar pautado na soberania popular. Suas origens estão nas constituições das cidades gregas, berço das atuais democracias, nas quais era freqüentemente utilizado, particularmente em Atenas.

Na Constituição Brasileira de 1988, existe previsão legal de consulta popular sob as designações de referendo e plebiscito nos artigos 49, inciso XV e 24, inciso VI (3), estando ambas condicionadas à prévia aprovação pelo Congresso Nacional. Distingue-se uma forma de consulta da outra, pelo fato do plebiscito se assentar em uma situação concreta já existente, e o referendo, sobre aquilo que se deseja estabelecer, ou não.

O plebiscito foi utilizado diversas vezes na história política brasileira. Há pouco tempo recorreu-se a esse mecanismo para apurar a vontade popular com relação à manutenção do regime presidencialista ou na mudança para o regime parlamentarista, sendo aprovado, por larga margem, o primeiro. Mais recentemente, também foi utilizada essa forma de consulta no caso da proibição da venda de armas no território brasileiro. Nos dois exemplos, supõe-se que o processo de consulta à população tenha sido precedido de esclarecimento prévio e amplo debate com a sociedade civil, discutindo-se todos os prós e contras e o maior benefício para a população, fato que parece não ter ocorrido, ao menos no primeiro caso.

A falta de esclarecimento e discussão prévios entre os diversos setores e segmentos da sociedade civil constitui um dos problemas dessa forma de consulta. Como exemplificado acima, o resultado da consulta popular pode variar enormemente com a quantidade e, principalmente, a qualidade da informação transmitida. Além disso, deve- 
se considerar como problema adicional o fato do direito de voto, no caso do referendo, não ser universalmente obrigatório em todos os países que o utilizam, circunstância que pode implicar em altos índices de abstenção nas urnas e, conseqüentemente, na diminuição da capacidade desse mecanismo de consulta refletir a vontade popular.

Pode-se observar um exemplo desse segundo problema na Suíça, única democracia ocidental realmente direta e não apenas representativa. Aquele país costuma recorrer freqüentemente ao referendo para avaliar todas as políticas sociais a serem implementadas pelo Estado, chamando os cidadãos às urnas pelo menos a cada três ou quatro meses. Não obstante, mesmo utilizando essa forma de consulta direta, que pressupõe a participação popular, os referendos suíços têm um alto grau de abstenção. Isso pode decorrer de certa indiferença dos cidadãos em relação às políticas públicas, de algum modo já suficientemente discutidas de forma democrática antes da sua implementação, ou de desinteresse, motivado por consultas repetidas, realizadas com demasiada freqüência.

No Brasil, o referendo não corre o risco da abstenção, já que o voto é obrigatório tanto nas eleições de representantes para os poderes Executivo e Legislativo, quanto nas consultas sobre aspectos específicos da legislação. A obrigatoriedade do voto parece relacionada ao temor da classe política em ensejar uma alta abstenção, se o referendo fosse desvinculado do voto obrigatório. Pode-se inferir até que a preocupação com a abstenção não se atenha a tal forma de consulta e que, uma vez facultada a não obrigatoriedade do voto, esse processo venha a refletir-se, depois, na votação para os próprios cargos parlamentares. A solução para tal apreensão seria, talvez, adotar procedimento semelhante ao implementado nos Estados Unidos da América (EUA), onde as consultas populares são realizadas simultaneamente às eleições parlamentares para determinados Estados, ou até mesmo, às presidenciais.

A médio e longo prazos pode-se elencar outros temas sociais de grande relevância, que deveriam também ser contemplados por essa forma de consulta. Entre eles podem ser destacados a eutanásia em pacientes terminais, o acesso universal e gratuito à saúde pública e privada, a descriminalização do uso de drogas e a instituição da pena de morte para crimes hediondos, apenas para citar alguns daqueles 


\section{Revista Brasileira de Bioética}

mais polêmicos, que movimentam os debates correntes. Para a consolidação e aperfeiçoamento da democracia é absolutamente necessário que a sociedade se manifeste sobre que tipo de política pública deseja ver implementada por seus governantes; estes, em tese, legitimamente eleitos pela sociedade e, portanto, representativos da vontade coletiva.

\section{Considerações finais}

A presente reflexão tem o objetivo de contribuir para levantar a questão sobre a importância do debate e da regulamentação de plebiscitos e referendos nacionais, visando esclarecer sobre que tipo de política pública a sociedade deseja ver implementada em seu benefício. A participação popular direta reflete o amadurecimento da democracia e parece ser o sistema mais adequado para definir a vontade social, no que tange às questões moralmente complexas.

É sabido que desde o Iluminismo Rousseau e Montesquieu defendiam idéias baseadas nos princípios da eqüidade e da justiça, sustentando que as leis devem derivar da vontade dos governantes em servir ao cidadão, e não o contrário, isto é, não devem ser impostas despoticamente de cima para baixo, contra a vontade da maioria.

\section{Referências}

1. Mori M. A moralidade do aborto: sacralidade da vida e o novo papel da mulher. Brasília: Editora UnB; 1997.

2. BRASIL. Lei 7.209/84. Código Penal. Diário Oficial da União, 13 jul. 1984a.

3. . Constituição. República Federativa do Brasil. Brasília, Senado Federal, 1988.

Recebido em: 15/3/2007 Aprovado em: 29/3/2007 